\title{
A comparative study of ultrasonography versus magnetic resonance imaging in the diagnosis of abnormally adherent low lying placenta
}

\author{
Mohd. Ashraf ${ }^{1}$, Humera Noor ${ }^{1}$, Asima Afzal ${ }^{1}$, Irfana Rasool ${ }^{2}$ \\ ${ }^{1}$ Department of Obstetrics and Gynaecology, Government Medical College, Srinagar, Jammu and Kashmir, India \\ ${ }^{2}$ Department of Medical Health, Srinagar, Jammu and Kashmir, India
}

Received: 21 February2016

Accepted: 18 March 2016

*Correspondence:

Dr. Humera Noor,

E-mail: drhumeranoor@gmail.com

Copyright: $\odot$ the author(s), publisher and licensee Medip Academy. This is an open-access article distributed under the terms of the Creative Commons Attribution Non-Commercial License, which permits unrestricted non-commercial use, distribution, and reproduction in any medium, provided the original work is properly cited.

\section{ABSTRACT}

Background: When placenta is implanted partially or completely over the lower uterine segment it is called as placenta previa. Abnormalities associated with placenta previa include placenta accreta, placenta increta and placenta percreta. Prenatal diagnosis of placental abnormalities was earlier difficult but now a day's placentography is done using gray scale ultrasonography and more recently magnetic resonance imaging with or without gadolinium has been explored as a modality to optimize diagnostic accuracy. The objective of this study was to compare the effectiveness of ultrasonography and magnetic resonance imaging in diagnosis of placental abnormalities in patients having low lying placenta. The Design of this study was a prospective study conducted in a tertiary care hospital.

Methods: This study was conducted on 100 admitted pregnant females with gestational age 30-37 weeks with low lying placenta (previa), haemodynamically stable and having past history of uterine surgeries like caesarean delivery, dilatation and curettage and myomectomy. After confirming gestational age and low lying placenta on Ultrasonography, the detailed USG study was done. All the patients in the study group underwent MRI which was performed without contrast.

Results: Among 100 cases, most of the patients were in the age group of 26-30 (52\%), the least common age group was 20-25 (4\%). Out of 100 studied cases 29 were gravid two with $20.6 \%$ associated PAD, 34 were Gravida three with $29.4 \%$ PAD, 21 were gravid four with $23.8 \%$ PAD. Among 100 studied cases, dilatation and curettage was absent in 37 cases, out of that 22 had undergone one caesarean section, 13 had undergone two caesarean section and 2 cases had undergone three caesarean section. USG showing sensitivity, specificity, positive predictive value (PPV) and negative predictive value (NPV) of 53.3, 90.0, 69.6 and $81.8 \%$ respectively. X2 $=22.266$ and $\mathrm{p}=0.00$. MRI showing sensitivity, specificity, positive predictive value (PPV) and negative predictive value (NPV) of 73.3, 91.4, 78.6 and $8.89 \%$ respectively. $\mathrm{X} 2=43.689$ and $\mathrm{p}=0.001$.

Conclusions: Prenatal diagnosis is a key factor in optimizing the counseling, treatment and outcome of patients with placental adhesive disorder. Any women with placenta previa and previous uterine surgery should undergo careful imaging to assess the presence of placental adhesive disorder. Magnetic resonance imaging appears better diagnostic aid as compared to ultrasonography in diagnosing placental adhesive disorder.

Keywords: Placenta, Ultrasonography, MRI, Caesarean

\section{INTRODUCTION}

The placenta is the connecting unit between mother and the foetus through the umbilical cord. Columbus first coined the term placenta which meant a circular cake in latin. ${ }^{1}$ The placenta is developed from two sources. The main component is foetal which develops from chorion frondosum and the maternal component consists of Decidua basalis. ${ }^{2}$ The placenta is normally attached to the upper part of the body of uterus encroaching to the 
fundus adjacent to the anterior or posterior wall with equal frequency. When placenta is implanted partially or completely over the lower uterine segment it is called as placenta previa. The incidence of placenta previa is 1 in 305 deliveries and among hospital deliveries the incidence range from $0.5-1 \% .^{3,4}$ Risk factors include advanced maternal age, multiparty, multifetal gestation, prior caesarean delivery and smoking. Abnormalities associated with placenta previa include placenta accreta, placenta increata and placenta percreta, which occur when the placenta is abnormally adherent to the uterine myometrium as a result of partial or complete absence of decidua basalis and nitabuchs's/Sincreta indicates invasion into the myometrium and placenta percreta indicates invasion up to serosa. Placenta accreta complicates approximately $0.9 \%$ of all the pregnancies with an estimated 10 fold increase over last 50 years. The incidence of placenta accreta has increased with the rising number of caesarean delivery. ${ }^{5}$

Prenatal diagnosis of placental abnormalities was earlier difficult but now-a-days placentography is done using gray scale ultrasonography and more recently magnetic resonance imaging with or without gadolinium has been explored as a modality to optimize diagnostic accuracy. Ultrasonographic finding of placental adhesive disorder (PAD) will be loss of retro placental hypo echoic clear zone, loss of the bladder uterine interface and presence of vascular lacunae. ${ }^{6,7}$ Although ultrasound remain the primary modality in the evaluation of placental implantation, in recent years there has been interest in the use of MRI. Features of placenta accreta on magnetic resonance imaging are focal thinning or absence of myometrium at the site of placental implantation. A modular interface between the placenta and uterus mass effect of the placenta on the uterus causing an outer buldge and loss of the tissue between the placenta and bladder wall. ${ }^{1}$ Pre-natal diagnosis of abnormally adherent placenta and other placental abnormalities in patients having low lying placenta and other risk factors helps to minimize the complication rate and the surgeon to plan for the type of resources needed at the time of delivery which include obstetric anaesthesia, blood and blood products, appropriate surgical expertise and postoperative intensive area.

Objective of this study was to compare the effectiveness of ultrasonography and magnetic resonance imaging in diagnosis of placental abnormalities in patients having low lying placenta.

\section{METHODS}

A This study was conducted in Government Lalla Ded Hospital which is a 500 bedded tertiary care hospital for obstetrics and gynaecology and is an associated hospital of Government Medical College, Srinagar, jammu and Kashmir, India. The study was conducted on 100 admitted pregnant females from June 2012 to May 2014 with gestational age 30-37 weeks with low lying placenta (previa), haemodynamically stable and having past history of uterine surgeries like caesarean delivery, dilatation and curettage and myomectomy. The other risk factors were high parity and increased maternal age. Consent was taken from all the patients. After confirming gestational age and low lying placenta on ultrasonography, the detailed USG study was done by radiologist using $3.5 \mathrm{MHz}$ curved array transducer or probe (Philips Medical Systems) to note the placental localization (grade of placenta previa) and evidence of any placental adhesive disorder like placenta accreta, placenta increta and placenta percreta.

The following imaging features on Ultrasonography were noted: loss of retro placental hypo echoic clear zone, loss of the bladder wall uterine interface and presence of placental lacunae (vascular spaces). All the patients in the study group underwent MRI which was performed without contrast on a 1-5-T whole body magnetic resonance imaging scanner (Siemens Medical Solution). The maternal pelvis was imaged in the axial, coronal and sagittal planes with a 6-channel body matrix and a slice thickness of $6 \mathrm{~mm}$. features of MRI to diagnose placental adhesive disorder like placenta accreta were: placenta previa, uterine bulging, heterogeneous signal intensity within the placenta, dark intra placental bands on T2weighted images, and focal interruptions in the myometrial wall. Tenting of the bladder and direct visualization of the invasion of pelvic structures by placental tissue were other features. All the patients diagnosed as placental adhesive disorder were explained nature and type of disorder and counseled about management.

\section{RESULTS}

This study was conducted on 100 admitted patients with low lying placenta/ placenta previa with previous one or more uterine surgery and other high risk factors. All patients underwent USG and MRI to diagnose abnormal adherence of placenta to myometrium.

Table 1: Age distribution in study population.

\begin{tabular}{|lll|}
\hline Age & n & $\%$ \\
\hline $20-25$ & 4 & 4 \\
\hline $26-30$ & 52 & 52 \\
\hline $31-35$ & 29 & 29 \\
\hline $36-40$ & 15 & 15 \\
\hline Total & 100 & 100 \\
\hline
\end{tabular}

Among 100 cases, most of the patients were in the age group of 26-30(52\%), the least common age group was $20-25(4 \%)$.

Out of 100 studied cases 29 were gravid two with $20.6 \%$ associated PAD, 34 were Gravida three with $29.4 \%$ PAD, 21 were gravid four with $23.8 \%$ PAD. 
Table 2: Gravidity of the study cases with percentage PAD.

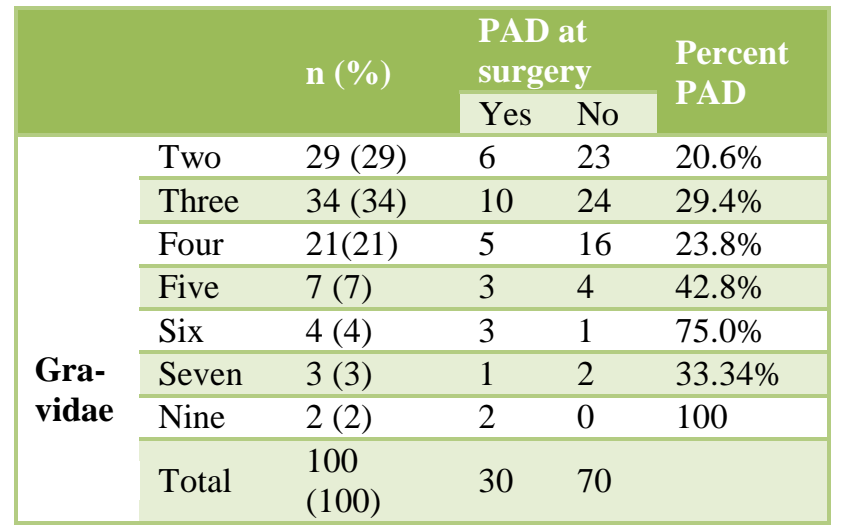

Among 100 studied cases, dilatation and curettage was absent in 37 cases, out of that 22 had undergone one caesarean section, 13 had undergone two caesarean section and 2 cases had undergone three caesarean section.

Among 30 patients confirmed as placental adhesive disorder (PAD) at surgery only 16 were diagnosed by ultrasonography as PAD, showing sensitivity as $53.3 \%$. Out of 70 patients who were negative for PAD at surgery only 63 were diagnosed by USG as no PAD showing a specificity of $90 \%$. Out of 23 patients diagnosed on USG as PAD only 16 were confirmed at surgery showing a positive predictive value $69.6 \%$ and out of 77 which were diagnosed as no PAD on USG only 63 confirmed at surgery as no PAD showing a negative predictive value $81.8 \%(\mathrm{p}=0.001)$.

Table 3: Relation between previous caesarean with previous D and C, myomectomy and PAD at surgery.

\begin{tabular}{|c|c|c|c|c|c|c|}
\hline & & \multicolumn{4}{|c|}{ Previous caesarean section } & \multirow[b]{2}{*}{ Tota } \\
\hline & & Absent & One & Two & Three & \\
\hline \multirow{4}{*}{$\begin{array}{l}\text { Dilatation and curettage (D and C) } \\
\text { following abortion }\end{array}$} & Absent & & 22 & 13 & 2 & 37 \\
\hline & One $\mathrm{D}$ and $\mathrm{C}$ & 31 & 8 & 5 & & 44 \\
\hline & Two D and C & 9 & 3 & 4 & & 16 \\
\hline & Three D and C & 1 & 2 & & & 3 \\
\hline Total & & 41 & 35 & 22 & 2 & 100 \\
\hline \multirow{2}{*}{ Previous myomectomy } & Absent & 41 & 33 & 22 & 2 & 100 \\
\hline & Present & & 2 & & & 2 \\
\hline Total & & 41 & 35 & 22 & 2 & 100 \\
\hline \multirow{2}{*}{ PAD at surgery } & Yes & $5(12.2 \%)$ & $13(37.1 \%)$ & $11(50 \%)$ & $1(50 \%)$ & 30 \\
\hline & No & 36 & 22 & 11 & 1 & 70 \\
\hline Total & & 41 & 35 & 22 & 2 & 100 \\
\hline
\end{tabular}

Table 4: Comparing diagnosis made on ultrasonography with preoperative findings.

\begin{tabular}{|c|c|c|c|c|c|}
\hline \multicolumn{6}{|c|}{ Placental adhesive disorder(USG)*PAD at surgery cross tabulation } \\
\hline \multirow{6}{*}{ Placental Adhesive Disorder (USG) } & & & PAD & urgery & \\
\hline & & & Yes & No & Total \\
\hline & \multirow{2}{*}{ Yes } & $\mathrm{n}$ & 16 & 7 & 23 \\
\hline & & $\%$ within PAD at surgery & 53.3 & 10.0 & 23.0 \\
\hline & \multirow{2}{*}{ No } & $\mathrm{n}$ & 14 & 63 & 77 \\
\hline & & $\%$ within PAD at surgery & 46.7 & 90.0 & 77.0 \\
\hline \multirow{2}{*}{ Total } & & $\mathrm{n}$ & 30 & 70 & 100 \\
\hline & & $\%$ within PAD at surgery & 100 & 100 & 100 \\
\hline \multirow{2}{*}{ Chi-square tests } & DF & $\mathrm{P}$ value & & & \\
\hline & 1 & 0.001 & & & \\
\hline
\end{tabular}

Among 30 patients confirmed as placental adhesive disorder (PAD) at surgery only 22 were diagnosed by MRI as PAD, showing sensitivity as $73.3 \%$. Out of 70 patients who were negative for PAD at surgery only 64 were diagnosed by MRI as no PAD showing a specificity of $91.4 \%$. Out of 28 patients diagnosed on MRI as PAD only 22 were confirmed at surgery showing a positive predictive value $78.6 \%$ and out of 72 which were diagnosed as no PAD on MRI only 64 confirmed at surgery as no PAD showing a negative predictive value $81.8 \%(\mathrm{p}=0.001)$. 
Table 5: Comparing magnetic resonance imaging findings with per operative findings.

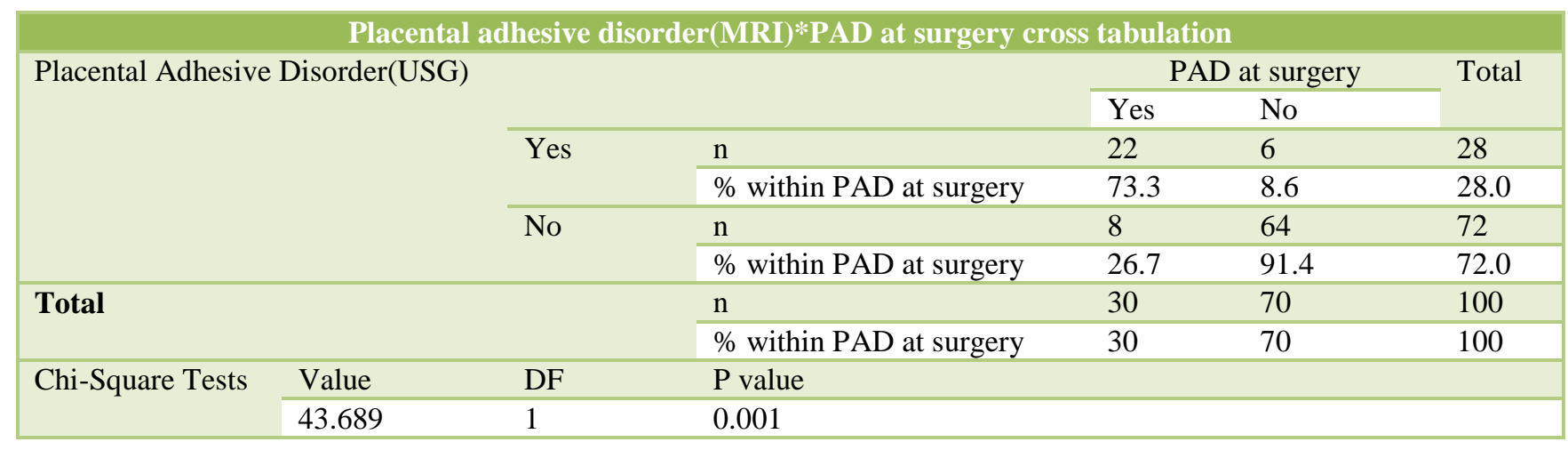

Table 6: Sensitivity, specificity, positive predictive value (PPV) and negative predictive value (NPV) of USG versus MRI.

\begin{tabular}{|lllllll|}
\hline & Sensitivity $\%$ & Specificity \% & PPV \% & NPV \% & Chi-square test $\left(x^{2}\right)$ & P \\
\hline USG & 53.3 & 90.0 & 69.6 & 81.8 & 22.266 & 0.001 \\
\hline MRI & 73.3 & 91.4 & 78.6 & 88.89 & 43.689 & 0.001 \\
\hline
\end{tabular}

USG showing sensitivity, specificity, positive predictive value (PPV) and negative predictive value (NPV) of 53.3, $90.0,69.6$ and $81.8 \%$ respectively. $\mathrm{X} 2=22.266$ and $\mathrm{p}=0.00$.

MRI showing sensitivity, specificity, positive predictive value (PPV) and negative predictive value (NPV) of 73.3, $91.4,78.6$ and $8.89 \%$ respectively. $\mathrm{X} 2=43.689$ and $\mathrm{p}=0.001$.

\section{DISCUSSION}

The incidence of placental adhesive disorder has increased over the past few decades. Optimal management of placenta accreta needs the prenatal diagnosis. The purpose of this study was to determine the sensitivity and specificity of both USG and MRI in diagnosing abnormal adherence of low lying placenta antenatally and to modify management accordingly. Most of the patients were in the age group of 26-30 years. Mean age of patients was 30.8 years with lowest 23 years and highest 39 years. Similar results were reported by Masselli $G$ et al they reported mean age of 31 years with range from 22 years to 38 years in their study group.Breen JL et al reported an average age of 29.5 years. Out of 100 studied cases 29 were gravida two with 6 cases of PAD, 34 were gravida three with 10 cases of PAD and 21 were gravida four with 5 cases of PAD. ${ }^{8,9}$ With increase in gravidity there was increased incidence of placenta accreta which can be compared with Lea Tuzovic et al who reported significant association with advanced maternal age, gravidity of 3 or more and previous uterine surgery. ${ }^{10}$ Out of 100 patients 41 had history of dilatation and curettage. Out of these 41 patients $5(12.5 \%)$ were detected having placental adhesive disorder per-operatively which was in accordance with the study done by Clark SL et al. ${ }^{11}$ In this study 35 patients had previous one caesarean section out of which only 13 were having placental adhesive disorder which amounts to $37.14 \%$ and 22 patients with previous two caesarean section, 11 had placental adhesive disorder which amount to $50 \%$. Similar results were reported by Clark SL et al. ${ }^{12}$ With $47 \%$ incidence of placenta accreta. William CB reported 40 percent accreta among patients with placenta previa and previous two caesarean section. ${ }^{7}$

Among 30 patients confirmed as PAD at surgery only 16 were diagnosed by USG as PAD, showing sensitivity of $53.3 \%$ and out of 70 patients who were negative for PAD at surgery only 63 were diagnosed by USG with no PAD showing a specificity of $90 \%$. Out of 23 patients diagnosed on USG as PAD only 16 were confirmed at surgery showing positive predictive value of $69.6 \%$ and out of $77 \%$ which were diagnosed as no PAD on USG only 63 were confirmed at surgery as no PAD showing a negative predictive value of $81.8 \% \quad(p=0.000)$. The sensitivity of USG in the present study $53.3 \%$ can be compared with the study done by W Christopher B who reported sensitivity of $50-80 \%{ }^{7}$

Among 30 patients confirmed as PAD at surgery only 22 were diagnosed by MRI as PAD, showing sensitivity of $73.3 \%$. Out of 70 patients who were negative of PAD at surgery only 64 were diagnosed by MRI as no PAD showing specificity of $91.4 \%$. out of 28 patients diagnosed on MRI as PAD only 22 were confirmed at surgery showing a positive predictive value of $78.6 \%$ and out of 72 patients who were diagnosed as no PAD on MRI only 64 confirmed at surgery as no PAD showing a negative predictive value of $88.8 \%$ whereas the results were comparable with study done by Warshak CR et al 
with sensitivity and specificity of MRI in detecting PAD as $88 \%$ and $100 \%$ respectively. Masselli $\mathrm{G}$ et al reported that MRI is highly accurate having sensitivity, specificity, positive predictive value and negative predictive value of $100 \%$. It is quite clear that MRI is more sensitive and specific in diagnosing PAD as compared to USG. ${ }^{8,12}$

\section{CONCLUSIONS}

Prenatal diagnosis is a key factor in optimizing the counselling, treatment and outcome of patients with placental adhesive disorder. Any women with placenta previa and previous uterine surgery should undergo careful imaging to assess the presence of placental adhesive disorder. Magnetic resonance imaging appears better diagnostic aid as compared to ultrasonography in diagnosing placental adhesive disorder.

\section{ACKNOWLEDGEMENTS}

Authors would like to thank all those women who participated in this study, department of obstetrics and gynaecology and department of radio diagnosis GMC, Srinagar, Jammu and Kashmir, India.

\section{Funding: No funding sources}

Conflict of interest: None declared

Ethical approval: The study was approved by the Institutional Ethics Committee

\section{REFERENCES}

1. Thakar DJ, Shah KM, Parikh D, Shah FA, Dave AN, Patel VB. Case report-Antepartum diagnosis of placenta accreta. Ind J Radiol Imag. 2004;14(4):431-2.
2. Dutta DC. Placental development; text book of obstetrics. $6^{\text {th }}$ ed. New cental book agency Calcutta; 2004:3:28.

3. Cunningham G, Leveno KL, Bloom SL, Hauth JC, Gilstrap LC, Wenstrom KD. William obstetrics: placenta previa, incidence, $22^{\text {nd }}$ ed. New York, McGraw Hill; 2005:27:820.

4. Dutta DC . Placenta previa, incidence: $6^{\text {th }}$ ed. New cental book agency Calcutta; 2004:18:243.

5. Dwyer BK, Victoria B, Lan T, Rao A, Caroll I, Barth $\mathrm{R}$ : prenatal diagnosis of placenta accreta, sonography or Magnetic resonance imaging. J Ultrasound Med. 2008;27(9):1275-81.

6. Angstemonn T, Gard G, Harrington T. Surgical management of placenta accreta: a cohort series and suggested approach. Am J of Obstet Gynecol. 2010;202(1):38:1-9.

7. William CB, Corteville JE. Placenta accreta: spectrum of US and MR imaging Finding. Radiographics. 2008;28(7):1905-16.

8. Masselli G, Brunelli R, Casciani E. Magnetic resonance imaging in the evaluation of placental adhesive disorder: correlation with color Doppler ultrasound. Eur Radio. 2008;18:1292-9.

9. Breen JL, Neubecker R, Gregori CA. Placenta accreta, increta and percreta. A survey of 40 cases. Obstet Gynecol. 1977;49;43-7.

10. Lea T, Josip D, Marcela I. Obstetric risk factors associated with placenta previa development: casecontrol study. Croat Med J. 2003;44:728-33.

11. Clark SL, Kooning PP, Phelan JP. Placenta previa/accreta and prior caesarean section. Obstet Gynecol. 1985;66:89-92.

12. Warshak CR, Eskander R, Hull AD. Accuracy of ultrasonography and magnetic resonance imaging in the diagnosis of placenta accreta. Obstetrics Gynecol. 2006;108:573-81.

Cite this article as: Ashraf M, Noor H, Afzal A, Rasool I. A comparative study of ultrasonography versus magnetic resonance imaging in the diagnosis of abnormally adherent low lying placenta. Int $\mathbf{J}$ Reprod Contracept Obstet Gynecol 2016;5:1428-30. 